\title{
Conflicto político interno, política exterior y el rol de América Latina: tensiones abiertas en el tercer gobierno peronista ${ }^{1}$
}

\author{
María Cecilia Miguez ${ }^{2}$
}

\section{Resumen}

La corriente política que se reflejó en el área de la política exterior y las relaciones internacionales cuando asumió Héctor Cámpora (1973) era producto de las transformaciones internas del peronismo y se proponía el inicio de una nueva política hacia América Latina. Prefiguraría también el acercamiento hacia Cuba y los intentos del nuevo gobierno argentino de avanzar hacia una reforma de la OEA y el sistema interamericano. En este artículo analizaremos la vinculación entre la dinámica política interna, la política exterior y las relaciones internacionales con América Latina. Veremos cómo durante ese gobierno y el de Juan Domingo Perón la política exterior volvió tener un giro antiimperialista dando relevancia a la región, pero donde la presencia de la dinámica de la Guerra Fría es fundamental para comprender las tendencias y contradicciones de la inserción internacional. En la política exterior se expresarían disputas más amplias, referidas al plano económico y político, en particular entre fracciones del peronismo. Así, la apelación a América Latina como espacio genuino de inserción irá modificando su contenido en un lapso de tiempo intenso y breve.

\begin{abstract}
The political current that was reflected in the area of the foreing policy and the international relations during the Héctor Cámpora's government (1973) was a product of the internal transformations of the Peronism. It was proposing the beginning of a new relation with Latin America. It would prefigure the approximation towards Cuba and the attempts of the new Argentine government of advancing towards a reform of the OEA and the inter-American system. In this article we will analyze the link between the political internal dynamics, the foreign policy and the international relations with Latin America. We will see how during this government and that of Juan Domingo Perón, the foreign policy returned to have an antiimperialistic draft, and to giving relevancy to the region. However, the dynamics of the Cold War is fundamental to understand the trends and contradictions of the international insertion. The foreign policy expressed the great disputes especially between fractions of the Peronism. This way, the appeal to Latin America like genuine space of insertion will be modifying his content in a space of intense and brief time.
\end{abstract}

\footnotetext{
1 Trabajo recibido el 24/07/2016. Aceptado el 02/11/2016.

${ }^{2}$ Licenciada en Ciencias Políticas y Doctora en Ciencias Sociales por la Universidad de Buenos Aires. Investigadora asistente del Consejo Nacional de Investigaciones Científicas y Técnicas. Contacto: mmccmiguez@gmail.com
} 
Palabras clave: Tercer gobierno peronista - Política exterior - América Latina - Conflicto político - Guerra Fría.
Keywords: Third peronist government Foreign policy - Latin America - Political conflict - Cold War

\section{Introducción}

El período que va desde 1969 hasta 1976 constituyó para la Argentina una etapa de auge de los movimientos políticos y sociales. Desde el Cordobazo en adelante asistimos a un significativo proceso de movilización social y política, vinculado con la modernización cultural, con el énfasis en el compromiso político, y con un escenario mundial marcado a fuego por el impacto de la descolonización de los países del tercer mundo y la Revolución Cubana (1959), el movimiento cristiano del Tercer Mundo (1967) y más contemporáneamente del Mayo Francés, el movimiento estudiantil mexicano y la denominada Revolución cultural de $1968 .{ }^{3}$ Todo ello fue contribuyendo a un proceso de radicalización ideológica que fue respondida con cada vez mayor represión por parte de la dictadura de la Revolución Argentina. Desde 1969, los jóvenes se lanzaron a la arena de la protesta. ${ }^{4}$ Asimismo ese auge derivó en una serie de contradicciones entre líneas políticas dentro del movimiento sindical y dentro del movimiento peronista en su conjunto, que irían abriéndose curso hasta transformarse en conflictos cada vez más abiertos.

Es objetivo de este trabajo estudiar el corto período entre la asunción de Héctor Cámpora ( 25 de mayo de 1973) y la muerte de Juan Domingo Perón (1 de julio de 1974) porque consideramos que allí se pueden rastrear, en el ámbito de la política exterior, ejes de conflicto y disputas entre intereses que se irían resolviendo en los años subsiguientes. Dicho período incluye tres presidencias, ya que el 13 de julio de 1973 Cámpora y Vicente Solano Lima (vicepresidente) presentaron sus renuncias, las cuales fueron inmediatamente aceptadas por el Congreso, con el objeto de realizar un nuevo proceso electoral donde Perón pudiera finalmente ser candidato. De acuerdo a la ley de acefalía presidencial, debía asumir la presidencia Alejandro Díaz Bialet, presidente provisional de la Cámara de Senadores, pero declinó, dejando lugar al presidente de la Cámara de Diputados Raúl Lastiri, yerno de José López Rega. Este último, figura cen-

\footnotetext{
${ }^{3}$ El concepto es de Fernand Braudel, (1993).

${ }^{4}$ Gordillo, (2007).
} 
tral por su protagonismo político como Ministro de Bienestar Social y luego como secretario privado de la presidenta María Estela Martínez de Perón (1974-1976), representaba el ala derecha y profundamente antiizquierdista del movimiento peronista, y conformaría la fuerza parapolicial Triple A. ${ }^{5}$ Las nuevas elecciones se realizaron el 23 de septiembre y la fórmula integrada por Perón y María Estela Martínez de Perón (Isabel) asumiría el 12 de octubre.

Entendemos que en el ámbito de la política exterior pueden estudiarse dichas contradicciones generadas tanto por la dinámica del sistema internacional como por la relación de fuerzas internas expresada en el Estado y en la relación entre Estado y sociedad civil. Es decir que se pretende inscribir los vaivenes de la política exterior en una dinámica más amplia de las relaciones e intereses económicos y conflictos políticos. Nos parece interesante vincular tanto la disputa entre las potencias del sistema internacional y sus vínculos domésticos, las posiciones de los distintos funcionarios que expresan líneas políticas en contradicción y la cuestión política en el plano de la sociedad civil movilizada. Todo ello, para evaluar las relaciones de cooperación, acercamiento, distanciamiento o rivalidad en la región latinoamericana.

Varios de los trabajos que abordan prolíficamente este período y que constituyen insumos fundamentales de este análisis han puesto el énfasis en distinguir elementos de quiebre y/o de continuidad. En este artículo queremos recuperar el entramado histórico para observar el devenir de las contradicciones abiertas en 1973. Más que buscar rupturas en un camino lineal, buscamos abordar el período desde su complejidad, para dilucidar la imbricación de conflictos políticos, económicos e internacionales.

\section{El regreso del peronismo y el escenario regional y mundial}

La vuelta del peronismo al poder sucedía en un contexto particular de la Argentina y cambiante respecto de la región latinoamericana. Luego de siete años de dictadura y frente a la indirecta proscripción de la candida-

\footnotetext{
${ }^{5}$ José López Rega se había desempeñado como cabo policial en las primeras presidencias de Perón, y era cercano al grupo Alianza Libertadora Nacionalista (ALN). A través de su proximidad con María Estela Martínez se desempeñó como guardaespaldas y finalmente como secretario de Perón durante el exilio. Ver Corigliano, (2007): 61 y Baschetti, (1996). En especial para un trabajo reciente sobre la ALN ver Furman, (2014).
} 
tura de Juan Domingo Perón ideada por el militar en el poder, Alejandro Agustín Lanusse, la fórmula del frente electoral triunfante (FREJULI) liderada por Héctor Cámpora y Vicente Solano Lima se imponía en las elecciones con un 49,6 porciento de los votos. ${ }^{6}$ La posición de Balbín fue la de apoyo al gobierno y de hecho fue interlocutor válido de muchas de las medidas. ${ }^{7}$

El general Perón utilizó a lo largo de los últimos años de su exilio, múltiples estrategias para la vuelta al poder, entre las que se destacaron sus vínculos con la Juventud Peronista, en especial, la Tendencia Revolucionaria. Por esa razón, la campaña electoral estuvo signada por un tono radicalizado, una retórica que se apoyaba en esos sectores movilizados más que en el tradicional sindicalismo peronista. ${ }^{8}$ Ello iba de la mano no sólo con un escenario internacional y regional ideológicamente progresista, sino con el aumento del peso relativo de esa organización en la estructura partidaria entre 1971 y 1972. Carlos Moneta distingue en su clásico trabajo sobre el período cuatro sectores diferenciables: un «peronismo ortodoxo» representado por las viejas figuras del partido protagonistas de los primeros gobiernos; el aparato de conducción sindical; un «peronismo familiar», es decir el círculo íntimo que rodeaba a Perón en el exilio, encabezado por la propia Isabel y López Rega; y finalmente grupos juveniles más radicalizado a los que se sumaban sectores obreros. ${ }^{9}$ Agrega además a un «sector tecnocrático e intelectuales reformistas». ${ }^{10}$

El triunfo del FREJULI representaba situaciones diversas para cada una de las fracciones del peronismo. Tal como afirma Tcach, para los viejos militantes peronistas era el fin de 18 años de exilio y proscripción, para los Montoneros era el resultado de una estrategia sintetizada en su lema «con los votos al gobierno, con las armas al poder» y para los militantes de la izquierda peronista, de corazón guevarista, era un paso hacia el sueño de una Argentina cercana al socialismo. ${ }^{11}$ La conformación del ministerio de Cámpora daba cuenta de la necesidad de equilibrar las fuerzas internas. Los sectores de la Tendencia tenían vínculo cercano con el canciller Juan

\footnotetext{
${ }^{6}$ Pucciarelli, (1999): 273.

7 Page, (1984): 258.

${ }^{8}$ Ello probablemente se debiera a la desconfianza que tenía Perón respecto de algunos líderes de la burocracia sindical respecto de la posibilidad de responder a los intentos de la dictadura de hacer una apertura condicionada. Ver Vázquez Ocampo (1989): 17.

${ }^{9}$ Moneta, (1979): 228.

${ }^{10}$ Moneta, (1979): 233.

11 Tcach, (2007): 60.
} 
Carlos Puig, el ministro del Interior, Esteban Righi y -en menor medidacon el ministro de Educación, Jorge Taiana. Por el contrario, el ministerios de Bienestar Social, bajo el mando de López Rega representaba una orientación de derecha que iría extendiendo su poder. ${ }^{12}$ Por lo tanto, en el caso de la política exterior podemos analizar la evolución y conflicto entre los sectores, a través de las gestiones de Puig (durante el gobierno de Cámpora) y Juan Carlos Vignes (canciller de Lastiri, Perón e Isabel Perón), representantes de líneas ideológicas distintas no solamente dentro del peronismo sino respecto de las estrategias de inserción internacional argentina en el contexto de la Guerra Fría.

Los últimos años de la autodenominada Revolución Argentina se habían caracterizado por un importante cambio de rumbo en la inserción internacional argentina y en la política exterior. El escenario de recrudecimiento de la competencia entre las potencias del mundo bipolar por el dominio de los mercados en todo el mundo y también en América Latina se reflejó también en el seno del estado y del gobierno dictatorial. A diferencia de la política llevada adelante por Juan Carlos Onganía (1966-1970), que implicaba en varios aspectos económicos e ideológicos una alineación con los Estados Unidos -aunque no en modo automático debido a la heterogeneidad de la coalición que conformaba el gobierno de la denominada Revolución Argentina- ${ }^{13}$, Lanusse de algún modo relativizó la concep-

${ }^{12}$ Page afirma que no se sabe cómo logró ser incluido en el gabinete, que probablemente ello se haya debido a la cercanía con Perón y con Isabel, pero que controlaría desde allí los nombramientos de su ministerio y los enormes fondos de los que disponía. El nombramiento de Lastiri, su hijo político, extendería su influencia. Page, (1984): 242.

${ }^{13}$ En cuanto a la caracterización de los vínculos entre el gobierno de Onganía y los Estados Unidos existen una serie de trabajos que discuten el grado de afinidad o alineamiento. Se coincide aquí con Rapoport y Laufer quienes afirmarn que a pesar de que el Departamento de Estado demoró 18 días en reconocer al gobierno de facto en función de las diferencias entre la CIA, el Pentágono y el propio Departamento, «en el plano de las relaciones internacionales se abrió el período de mayor proximidad a los intereses económicos y geopolíticos de los Estados Unidos en la historia argentina. Rapoport y Laufer (2000): 47. Por su parte Morgenfeld afirma que la mayor afinidad estuvo en el plano ideológico, lo que se confirma con el hecho de que entre 1964 y 1970, más de 2000 oficiales argentinos recibieron entrenamiento en Estados Unidos y en la zona del Canal de Panamá Sheinin, (2006): 147 y con la propuesta argentina de institucionalizar un comité consultivo de defensa, un novedoso órgano militar interamericano, a pesar de que la Casa Rosada había resistido este tipo de instituciones supranacionales desde 1947 Morgenfeld, (2014): 530. Las diferencias se expresaron más bien en el plano estratégico, donde la dictadura contemplaba los intereses de ciertos sectores de las FFAA, como los casos de la negativa a ratificar los tratados de No Proliferación de Armas Nucleares y de Tlatelolco. De otra parte, Cisne- 
ción de las «fronteras ideológicas» e inició un giro en la política económica que se expresó en la firma de un acuerdo comercial con la Unión Soviética en 1971 con cláusula de nación más favorecida para ambas partes y en el establecimiento de relaciones diplomáticas con la República Popular China en 1972. A ello se sumaron las visitas al Chile de Salvador Allende. Ello no implicaba una transformación ideológica ni el abandono de la noción del enemigo interno comunista - recordemos que se trataba de un gobierno dictatorial dispuesto a perseguir y reprimir toda manifestación política volcada hacia la izquierda- sino de alineamientos internacionales y de proyectos de inserción. La política de apertura se vinculaba tanto con la política de distensión de Nixon como con el proceso político interno en las Fuerzas Armadas Argentinas. ${ }^{14}$ El canciller Luis María De Pablo Pardo afirma lo siguiente en una entrevista recientemente publicada:

«El principio del gobierno del general Onganía era la Doctrina de Seguridad Nacional, o aparentemente eso parecía. Es decir, la ruptura de las fronteras ideológicas supone también la ruptura con la Doctrina de la Seguridad Nacional, más teniendo en cuenta que hay una situación interna explosiva. Se había producido ya el «Cordobazo». La situación estaba caldeada. Comienza a visualizarse dentro de los comandantes en jefe un cambio en ese sentido. Usted lo ve en las reuniones, la Doctrina de Seguridad Nacional no va más o es algo que está un poco perimido, hay que empezar a ir cambiando. Esto es una cosa que ocurre en el período de Lanusse, no en el período de Levingston ${ }^{15}$

ros y Escudé consideran que la política llevada adelante por Onganía no debe interpretarse como alineada directamente con los Estados Unidos -sino más bien como anticomunista y antisoviética- ni tampoco debe afirmarse la existencia de una ruptura abrupta respecto del período de Lanusse (2000): 105-106.

${ }^{14}$ Se relaciona con la visita de Nixon a China en 1972 en el contexto de la denominada diplomacia del ping pong y esa etapa de relativa distensión, sin embargo, las misiones comerciales a la URSS son anteriores (1970) y el acuerdo firmado por Antonio Estany Gendre fue en junio de 1971. Ver Rapoport (2016): 26.

${ }^{15}$ De Pablo Pardo, (2016): 365. En la entrevista, De Pablo Pardo afirma que esa ruptura de las fronteras ideológicas no representó un cambio abrupto sino un nuevo modo de expresar el interés nacional. Respecto del tratado comercial firmado con la Unión Soviética directamente afirma: «eso forma parte de la idea de la ruptura de las fronteras ideológicas, por qué no vamos a comerciar con un país que tiene otra ideología, cuando el interés nacional virtualmente nos impulsa a que ello no se tenga en cuenta». Rapoport, (2016): 372-373. 
Por estas razones, varios autores han coincidido en afirmar que Lanusse inició lo que se conoce como «apertura hacia el Este». Una tendencia se iría profundizando en el primer año del gobierno peronista y perduraría de la mano de la gestión de José Ver Gelbard, pero combinada y en tensión con un componente político nuevo y distintivo: el rol de Latinoamérica en la política exterior argentina y la expresión del antiimperialismo que caracterizó en su génesis al movimiento peronista.

El panorama político regional reflejaba una América Latina dividida y disputada. Los gobiernos de Allende, en Chile, el Guillermo Rodríguez Lara de Ecuador y el de Juan Velazco Alvarado en Perú, expresaban de modos muy diversos y hasta contradictorios, aspiraciones de cambio y transformación ${ }^{16}$ y en cuanto al comportamiento internacional esos dos gobiernos mostraron defensa de su autonomía respecto de los Estados Unidos. ${ }^{17}$ Estos tres países formaban parte de recientemente puesto en marcha Pacto Andino, una estrategia de integración particular, que priorizaba el crecimiento e impulso a la industrialización sustitutiva y la planificación estatal como herramienta central del desarrollo. Constituía un modelo alternativo al del la ALALC, donde había finalmente hegemonizado la estrategia comercialista ${ }^{18}$ y sus políticas representaban una opción a la hegemonía de los Estados Unidos en el continente. Por otro lado, Brasil, Paraguay, Bolivia y Uruguay, con la crisis y el golpe asumido por Bordaberry, se alineaban con la lucha anticomunista, antipopulista en el marco de la Doctrina de Seguridad Nacional.

En este complejo escenario, el peronismo retornaba al poder en un contexto de absoluto auge de la movilización política y social en la Argentina. La política exterior de Cámpora y luego de Perón buscarían apoyo en los tres primeros gobiernos citados (Perú, Ecuador y Chile). Pero el cambiante escenario demostraría que las potencias del sistema internacional y en especial los Estados Unidos estaban dispuestos a impedir cualquier escenario de reforma económica que contraviniera sus intereses. La aparente mayor flexibilidad del período de la detente se mostraba limitada y comenzaba a ponerse en cuestión para el escenario latinoamericano. América Latina era un espacio disputado y propicio para el avance de los intereses de diversas potencias, incluida la URSS.

\footnotetext{
${ }^{16}$ Ansaldi y Giordano, (2014): 370.

${ }^{17}$ En 1973 ambos países apresaron pesqueros de los Estados Unidos en su mar territorial, como ejemplo de autonomía Moneta, (1988): 229.

${ }^{18}$ Para un análisis de las estrategias en debate en oportunidad de la conformación de la ALALC ver Musacchio, (2006).
} 


\section{La asunción de Cámpora, los antecedentes de la política exterior y los signos de nueva etapa}

El acto de toma de posesión del cargo presidencial de Héctor Cámpora constituyó un símbolo del cambio del alineamiento político de la Argentina. Prueba de la relevancia mundial del hecho fue la asistencia de 86 delegaciones internacionales a la asunción presidencial. ${ }^{19}$ Tres delegaciones incluían a los primeros mandatarios: la de Uruguay, con la presencia de Bordaberry, y los dos protagonistas de la jornada: el presidente chileno Allende y su par cubano, Osvaldo Dorticoìs. Ese protagonismo y la lectura que en la política interna se haría de estas dos últimas presencias, son elementos que ejemplifican el nuevo escenario. Quizás las ausencias también sean elocuentes respecto del panorama político interno. El dictador boliviano Banzer no asistió por la compleja situación interna de su país, enviando a su canciller, y el Secretario de Estado de Estados Unidos, William P. Rogers, quien se encontraba cerrando una amplia gira por América Latina, no pudo presenciar el acto de asunción porque una multitud que coreaba consignas anti-imperialistas le impidió llegar hasta la casa de gobierno. ${ }^{20}$ Algo similar le sucedió al uruguayo Bordaberry, quien fue objeto de abucheadas por parte de las multitudes en la plaza, lo que llevó al propio Cámpora a disculparse luego. ${ }^{21}$ Conocidas son las variadas manifestaciones de festejo que se adueñaron de la escena política del 25 de mayo de 1973, por parte, principalmente, de la juventud peronista ${ }^{22}$.

En su discurso, el presidente electo hizo especial hincapié en la defensa del antiimperialismo y del principio de no intervención y en la crítica a la OEA, así como en la necesidad de que la Argentina tuviera relaciones con todos los países, incluida Cuba. El clima político del período y la vinculación entre política interna y relaciones internacionales se confirmó con la significativa participación de Dorticós en la conmemoración del cuarto aniversario del Cordobazo, el 29 de mayo. Allí, uno de los cánticos escuchado fue «Cuba y Perón, un solo corazón». Del «De Gaulle, Perón, un solo corazón» de 1964 a esta nueva versión, había una importante dife-

\footnotetext{
19 «Ochenta y seis naciones se hicieron representar en la ceremonia de la transmisión de mando», Clarín, 26/05/1973, p. 12.

${ }^{20}$ Svampa, (2003): 395.

${ }^{21}$ «Destaca la prensa uruguaya inconvenientes de Bordaberry en los actos del 25 de mayo», Clarin, 28/05/1973, p. 6.

${ }^{22}$ Ver Bonasso, (2006) .
} 
rencia. ${ }^{23}$ Era el reflejo de la izquierdización de un sector del peronismo, y también de la reorientación de las relaciones internacionales argentinas. ${ }^{24}$

La presencia y ovación a estos dos visitantes -Dorticós y Allendeponía sobre la mesa la discusión sobre qué tipo de «unidad continental» buscaba implementar el gobierno. La orientación latinoamericanista de Cámpora reflejaba claramente un giro a la izquierda que muchos sectores no estaban dispuestos a tolerar, incluso dentro del propio partido y movimiento peronista. Política exterior y conflicto político interno se entrecruzaban.

Como se afirmaba más arriba, la tendencia hacia el abandono de la idea de las «fronteras ideológicas» en el campo de las relaciones económicas internacionales no era nueva. Eduardo Mc Loughlin, canciller de Lanusse, fue el encargado, por ejemplo, de normalizar las relaciones diplomáticas, consulares y económicas entre los gobiernos de la Argentina y Cuba, en el marco de toda la estrategia de acercamiento a los países «del Este». Ello se relacionaba con cuestiones económicas que excedían las diplomáticas. Por diversos factores, una poderosa fracción de la clase dominante argentina comenzó a promover desde 1970 la negociación de un tratado comercial con la Unión Soviética. Entre esos factores se encontraban los intereses de negocios vinculados a dicha superpotencia que habían venido creciendo desde el período desarrollista, y las dificultades para colocar los productos en la Europa Comunitaria. Este viraje culminará en una nueva relación triangular hacia mediados de la década de 1970, consolidado por la dictadura militar implantada en 1976, ocupando la Unión Soviética durante unos años el vértice anteriormente por Europa occidental y antaño por Inglaterra. ${ }^{25}$

Pero la asunción de Cámpora, a diferencia del período dictatorial, permitió que el gobierno cubano demostrara su afinidad con el nuevo presidente y con la etapa que parecía abrirse. A las cuestiones económicas de la inserción internacional argentina, que continuarían su marcha, se sumaba ahora una afinidad política que iría en un carril paralelo y que, a diferencia de las primeras, no se extendería en el tiempo. La Argentina reinterpretaba la Tercera Posición histórica del peronismo a través de la conciencia de pertenecer al Tercer Mundo y a una Latinoamérica en cami-

\footnotetext{
${ }^{23}$ Míguez, (2013).

${ }^{24}$ Ver notas de Alonso, (1973):7 y Portantiero, (1973).

${ }^{25}$ Para las relaciones bilaterales entre la Argentina y la Unión Soviética en el período ver: Rapoport, (1995); Vacs, (1984) y Laufer y Spiguel, (1998).
} 
no a la Liberación. Es decir que la identificación con esos países era claramente ideológica. Tal como se preanunciaba, los lazos diplomáticos con la isla se reanudaron el 28 de mayo a través de una declaración conjunta entre los cancilleres Juan Carlos Puig y Raúl Roa García, de Argentina y Cuba respectivamente. Se cerraba la etapa iniciada con la ruptura de relaciones de febrero 1962. La prensa del 29 de mayo publicaba, además, la explícita intención de gobierno de reanudar las relaciones con Alemania Oriental y Corea del Norte. ${ }^{26}$

No era un detalle menor el hecho de que los únicos otros dos países que habían restablecido relaciones con la isla caribeña eran el Chile de Allende y el Perú de Velazco Alvarado. En efecto, las características de la asunción de Cámpora fueron una señal que sería rápidamente interpretada a nivel mundial. Ello puede apreciarse en la repercusión en la prensa española, estadounidense, francesa y, por supuesto, regional, reproducida en el diario La Opinión. En especial, el periódico The Guardian, a través de la pluma de su periodista Richard Gott, publicó que «lo que da importancia a la vuelta del peronismo, es que, pese a su pasado político, el movimiento tiene ahora un neto cariz de doctrina de izquierda antiimperialista». ${ }^{27}$

\section{El renovado rol de América Latina}

En el mensaje presidencial que Cámpora dio en el día de la asunción afirmó que la Argentina propugnaría «una relación estrecha con los países del Tercer Mundo y en especial con los de América Latina», ${ }^{28}$ y que su gobierno sería «invariablemente solidario con las luchas antiimperialistas que llevan a cabo los Pueblos para abolir las viejas y nuevas formas de colonialismo y nunca tomará partido por los Gobiernos o Naciones explotadoras». ${ }^{29}$

La apelación a la «Liberación» constituyó una parte esencial de dicho discurso, donde podía evidenciarse que la vinculación con América Latina tenía, en esos términos, una vocación política distinta, de carácter no solamente instrumental y pragmático, no solamente antiimperialista,

\footnotetext{
${ }^{26}$ «Las relaciones con Cuba se reanudan», La Nación, 29/05/1973, p. 1.

${ }^{27}$ Citado en «Comienza un desafío al colonialismo y al imperialismo en América Latina», La Opinión, 26/05/1973, p. 2.

${ }^{28}$ Cámpora, (1973): 19.

${ }^{29}$ Cámpora, (1973): 18.
} 
sino claramente volcada discursivamente hacia la superación del orden establecido.

Más allá de la discusión sobre el contenido de la Tercera Posición que no solamente tuvo carácter pragmático sino también contenido antiimperialista- ${ }^{30}$ cierto era que la apelación a la integración tenía un carácter novedoso. En términos económicos, el presidente sostuvo en su mensaje la idea de una integración continental como una estrategia que debía reforzar -y no debilitar- las autonomías nacionales y colocó como paradigma el modelo de integración del Pacto Andino. Se refirió a la necesidad de la integración como instrumento para resolver las presiones de las potencias, de sus inversiones y de la depredación de los recursos naturales que éstas realizan. ${ }^{31}$ Así se anunciaba la intención de un viraje respecto del modelo de la Asociación Latinoamericana de Libre Comercio. «En particular y debido a las carencias de la ALALC, los países hermanos del Pacífico se han comprometido en un programa integrativo de auténtica Liberación» ${ }^{32}$.

También estaba presente en el discurso el fin de las fronteras ideológicas y la intención de restablecer las relaciones con Cuba. Por último, respecto del continente europeo, el nuevo presidente afirmó que esa vinculación «merecerá una atención especial por el profundo nexo ya existente en lo histórico, lo cultural y lo económico, en la medida en que, sobre la base de la aceptación de nuestras decisiones políticas, estén decididos a apoyarnos en nuestra lucha por la liberación».33

La estrategia del peronismo en general se centraba en una inserción multipolar con eje en Europa (pretendiendo reeditar las condiciones de la tradicional relación triangular), con América Latina como región prioritaria y sumando al Tercer Mundo, China Popular, Japón y los países socialistas del Este. ${ }^{34}$ Sin embargo, la relación con Europa era central particularmente para Perón, quien tuvo expectativas de recibir inversiones provenientes del viejo continente como modo para obtener un margen de maniobra mayor en el contexto de la disputa entre las potencias del orden bipolar. Era una estrategia multilateral que se diferenciaba de la pretendida por sectores de la denominada izquierda nacional. Para la línea predomi-

\footnotetext{
${ }^{30}$ Para un análisis exhaustivo de la Tercera Posición ver Rapoport y Spiguel, (2009).

${ }^{31}$ Cámpora, (1973): 19.

${ }^{32}$ Cámpora, (1973): 20.

${ }^{33}$ Cámpora, (1973) 23.

${ }^{34}$ Moneta, (1979): 236.
} 
nante durante el gobierno de Cámpora, la prioridad era la de los gestos políticos cercanos a una América antiimperialista y la profundización de la vinculación económica y comercial con los países del Este. Un informe de los Estados Unidos indicaba a pocos días de la asunción de Cámpora:

«Los peronistas esperan aumentar sus relaciones con Europa y los aportes del capital europeo para sustituir el dinero estadounidense. También tienen la intención de hacerse cargo de al menos algunas empresas de Estados Unidos y forzar la salida de algunos bancos estadounidenses. Ellos no tienen tanto la intención de confrontar o aislarse de los Estados Unidos sino de demostrar su independencia. En este sentido, se unirán a los gobiernos de Perú, Chile y México, que ya se han movido en esta dirección». ${ }^{35}$

Los pocos días del gobierno de Cámpora fueron especialmente prolíficos en el área de la política exterior, en especial gracias a la coincidencia entre la orientación del Ministerio de Economía -teniendo en cuenta que Gelbard era además el líder de la Confederación General Económica (CGE), asociación que representaba a la mediana industria nacional-y la Cancillería.

En línea a profundizar la posición argentina en relación al tema cubano, se iniciaron negociaciones económicas. Así, finalmente el 4 de agosto de 1973 el ministro de economía, José Ver Gelbard, ya durante la presidencia provisional de Raúl Lastiri, anunció que la Argentina otorgaría a Cuba un préstamo de seis años por un monto anual de 200 millones de dólares, para la adquisición en nuestro país de maquinaria liviana, especialmente del sector automotriz y agrícola. ${ }^{36} \mathrm{El}$ primer antecedente comercial había sido la venta de 50.000 toneladas de maíz en el mes de julio. En efecto, el crédito otorgado por la Argentina sería el mayor destinado a un país de América Latina. ${ }^{37}$ La confirmación de este crédito a la isla daba cuenta de la intención argentina de ocupar un rol de proveedor industrial en un nuevo bloque latinoamericano ${ }^{38}$.

\footnotetext{
${ }^{35}$ Foreign Relations of the Unites States (1969-1976), Volume E, Part 2, South America, 1973-1976, Memorandum Prepared in the Office of Current Intelligence, Central Intelligence Agency, «Peronism in Power», Washington, June 21, 1973, p. 15 [traducción propia].

36 «Argentina otorgó a Cuba un crédito de 200 millones de dólares y está en vías de integrarse al Grupo Andino», La Opinión, 07/08/1973.

${ }^{37}$ Ramírez, (1973): 12.

${ }^{38}$ Horowicz, (1973): 11.
} 
Por encima de esas declaraciones es significativo el análisis que hace Moneta respecto de otros objetivos a los que la medida buscaba responder. El autor destaca el protagonismo de Gelbard en la decisión, su propia vinculación con las industrias ligadas al sector automotriz, el beneficio para las empresas norteamericanas y la relación entre el crédito y la apertura hacia el Este. ${ }^{39}$

En términos políticos, y más allá de la renuncia de Cámpora y el interregno de Lastiri, incluso durante la tercera presidencia de Juan Domingo Perón, el líder defendería la reincorporación de Cuba al sistema interamericano. Lo haría en sus intervenciones en la Sexta Sesión Extraordinaria de la Asamblea General de la ONU, realizada en Nueva York y también en abril de 1974, en la Tercera Asamblea General de la OEA, en Washington. Pero los gestos más contundentes en términos ideológicos fueron la presentación del Embajador Jorge Vázquez (Subsecretario de Relaciones Exteriores) en el mes de junio, en la Reunión de Lima de la OEA y, en el mes del septiembre, la posición del General Carcagno en la Décima Conferencia de Ejércitos Americanos realizada en Caracas -si bien esta última se produjo ya durante la presidencia de Lastiri.

En Lima, Vázquez expuso que la Argentina estaba «dispuesta a asumir plena y lealmente su responsabilidad histórica en la tarea común de la liberación latinoamericana» y que «para nuestro país el pluralismo revolucionario supone, en nuestro continente, la abolición definitiva de todo tipo de instrumento que excluya a Cuba de la hermandad latinoamericana». ${ }^{40}$ Refiriéndose a la relación histórica entre Estados Unidos y los países de América Latina, sostuvo «no puede existir una relación madura cuando existen intereses distintos y no pocas veces contrapuestos» ${ }^{41}$ y que «no hay política común al opresor y al oprimido. No hay foro que pueda abarcar la pretensión imperialista y el deseo de ser libres». ${ }^{42}$ Esa posición generó el

\footnotetext{
${ }^{39}$ Moneta, (1979): 253.

${ }^{40}$ Archivo del Ministerio de Relaciones Exteriores y Culto (AMREC), Fondo Archibaldo Lanús, AH 0003, Serie 65, C 72 A 69, CARPETA: TIAR EXP CUBA II, DOCUMENTO: Exposición del presidente de la Delegación de la Argentina, Jorge Vázquez. OEA Sesión Plenaria. Comisión especial para analizar el Sistema Interamericano y proponer medidas para su reestructuración (CEESI) 21/6/1973, p. 78.

${ }^{41}$ Archivo del Ministerio de Relaciones Exteriores y Culto (AMREC), Fondo Archibaldo Lanús, AH 0003, Serie 65, C 72 A 69, CARPETA: TIAR EXP CUBA II, DOCUMENTO: Exposición del presidente de la Delegación de la Argentina, Jorge Vázquez. OEA Sesión Plenaria. Comisión especial para analizar el Sistema Interamericano y proponer medidas para su reestructuración (CEESI) 21/6/1973, p. 80.

${ }^{42}$ Archivo del Ministerio de Relaciones Exteriores y Culto (AMREC), Fondo Archibaldo
} 
descontento particularmente de los sectores más conservadores del peronismo y generaría el rápido desplazamiento del equipo de Puig. ${ }^{43}$

Por su parte, ya en septiembre de 1973, Carcagno reflejó la intención de alinear a la Argentina con los países del Pacto Andino, apoyando fervientemente la tesis reformista del Tratado Interamericano de Asistencia Recíproca, apoyada por Perú, Ecuador, Venezuela, Colombia y Panamá, que se negaba a instaurar mecanismos regionales de represión controlados por los Estados Unidos ${ }^{44}$.

Merecen ser destacadas durante la breve presidencia de Cámpora las políticas orientadas a recomponer la situación en la Cuenca del Plata. Se denunció el denominado acuerdo de Nueva York que se había establecido en 1972 entre Brasil y Argentina. Se reiniciaron negociaciones con Paraguay para el aprovechamiento de Apipé y para el proyecto brasileño-paraguayo de la represa de Itaipú. Se impulsaron gestiones para establecer industrias conjuntas con Bolivia y programas de alto grado de complementación económica con Uruguay. Los ejemplos son una planta de montaje de tractores agrícolas y una industria de pesticidas. Con Chile se gestaron proyectos de interconexión eléctrica, explotación coordinada de yacimientos de gas y cobre y vinculación fronteriza. ${ }^{45}$ Por ora parte, y con asistencia de la Unión Soviética, se impulsó el proyecto de Paraná Medio ${ }^{46}$. Sin embargo, las diferencias internas que analizaremos entorpecieron muchas de las estrategias.

\section{Contradicciones internas, políticas exteriores en pugna}

La tensión entre las relaciones internacionales y las vertientes del peronismo se entramaban. Ello se verificaba tanto en la sociedad civil como

Lanús, AH 0003, Serie 65, C 72 A 69, CARPETA: TIAR EXP CUBA II, DOCUMENTO: Exposición del presidente de la Delegación de la Argentina, Jorge Vázquez. OEA Sesión Plenaria. Comisión especial para analizar el Sistema Interamericano y proponer medidas para su reestructuración (CEESI) 21/6/1973, p. 81.

${ }^{43}$ Moneta, (1979): 245.

${ }^{44}$ Archivo del Ministerio de Relaciones Exteriores y Culto (AMREC), Fondo Archibaldo Lanús, AH 0003, Serie 65, C 72 A 69, CARPETA: Cuestiones Militares Interamericanas, DOCUMENTO: Comando en Jefe del Ejercito. Jefatura V. Pol y Est. Informe Final sobre la Xma Conferencia de Ejércitos Americanos. Secreto. Setiembre de 1973. «Palabras pronunciadas por el Comandante en Jefe del Ejército Nacional Argentino, Teniente General Jorge Raúl Carcagno en la X Conferencia de Ejércitos Americanos».

${ }^{45}$ Moneta, (1979): 265.

46 Puig, (1988): 37. 
en el seno del Estado. La preocupación por la avanzada de «los imperialismos» en términos del propio general Perón, se correspondía con la posición de algunas centrales sindicales, reacias a la vinculación del movimiento peronista con las influencias socialistas y castristas. ${ }^{47}$

Luego de la renuncia de Cámpora, los desplazados fueron Righi, responsable del «devotazo» y Puig. Ambos fueron reemplazados por Alberto Vignes y Benito Llambí, respectivamente. El cambio de línea era contundente en ambas áreas. De allí en más la tensión giraría fundamentalmente cada vez más fuertemente entre López Rega y Gelbard. El nuevo canciller Vignes estaba vinculado al primero de ellos, y respondía a un peronismo tradicional que no estaba dispuesto a sostener la línea desplegada por Puig y por Gelbard. El propio Puig afirma que luego de su desplazamiento Vignes inició una especie de persecución personal contra él, desacreditándolo en cada oportunidad. ${ }^{48}$ En efecto, el nuevo canciller se oponía a la apertura hacia el Este y las diferencias distaban de ser solamente personales. Retiró la orden de su antecesor de hacer renunciar a los embajadores designados por los gobiernos militares de la Revolución Argentina y se rodeó de figuras poco cercanas incluso al peronismo. ${ }^{49}$ Implicaba distanciarse de la orientación sostenida por Gelbard cuyo principal apoyo era Tettamanti -quien ocupó los cargos de subsecretario de Relaciones Económicas Internacionales de la cancillería y secretario de Relaciones Económicas Internacionales- lo que demostraba la continuidad de una línea política ya instalada en el período de Lanusse. Cisneros y Escudé sostienen que esas disputas ideológicas -y en parte personales- se resolvieron a favor de Gelbard mientras vivió Perón, lo que se reflejó en la misión comercial de mayo de 1974 a la Unión Soviética, Polonia, Hungría y Checoslovaquia, en los citados acuerdos con Cuba e incluso en el ingreso de la Argentina al Movimiento de Países no Alineados. Sin embargo, el «ordenamiento» integral del Servicio Exterior y de su Instituto fue una estrategia de Vignes para eliminar a los funcionarios vinculados a la línea ideológica de Puig. ${ }^{50}$

El viraje producido con la llegada de Vignes a la cancilería fue percibido por los Estados Unidos en oportunidad de la reunión entre el nuevo

\footnotetext{
${ }^{47}$ Ver «Impidieron a gritos los concurrentes a un asado ofrecido a gremialistas extranjeros que se brindara por el Che Guevara», La Razón, 03/06/1973.

${ }^{48}$ Puig, (2016): 429.

${ }^{49}$ Cisneros y Escudé, (2000): 163.

${ }^{50}$ Cisneros y Escudé, (2000): 164.
} 
ministro y Henry Kissinger. Allí Vignes sostuvo que «la llegada de Perón al poder abría un nuevo período para la relaciones con los Estados Unidos», que la cuestión del crédito y el comercio con era «puramente una operación financiera, destinada únicamente a permitir que la industria de la maquinaria agrícola argentina pueda operar a una capacidad completa» y que en lo que hace a la reforma de la OEA «sería posible llegar a un acuerdo entre ambos países»..$^{51}$

Desde la asunción de Perón comenzó a hablarse de la posibilidad del viaje del presidente a Nueva York y de un plausible encuentro con el par estadounidense Richard Nixon. Sin embargo, ese encuentro nunca prosperó si bien fue barajado como posible e incluso deseable por algunos funcionarios de la embajada de los Estados Unidos.

Respecto del escenario internacional, en oportunidad del golpe contra Salvador Allende, también puede evaluarse la relación entre política interna, política exterior y condicionantes del escenario internacional. Las primeras declaraciones de Perón a la prensa afirmaban que se trataba de una situación lamentable para el continente, que no se trataba de un fracaso de Allende, que suponía el involucramiento de los Estados Unidos en el golpe y que si la dictadura no tenía la sabiduría de llamar a elecciones pronto el pueblo enfurecería. ${ }^{52}$ Sin embargo, dos días después justificó la falta de condena formal a la interrupción del proceso democrático diciendo: «soy enemigo de meterme en casa ajena (...) nosotros no reconocemos ni dejamos de reconocer. Seguimos adelante y nos entendemos con el que dice que gobierno aunque no gobierne». ${ }^{53}$ En efecto, la cancillería reconoció al nuevo gobierno el 19 de septiembre, justificándose con la doctrina Estrada. Perón temía un golpe similar en la Argentina, y consideraba que las posiciones «apresuradas» de los sectores de izquierda podrían contribuir negativamente. ${ }^{54}$

\footnotetext{
${ }^{51}$ Foreign Relations of the Unites States (1969-1976) Volume E-11, Part 2, Documents of South America 1973-1976. Memorandum of Conversation. Foreing Minister Alberto Vignes, Secretary Kissinger, Neil Seidenman, Interpreter, New York, October 5, 1973., p. 19-22. [traducción propia]

52 «Perón se refirió a los hechos de Chile», La Nación, 13/09/1973.

53 «Perón se refirió a diversos temas», La Nación, 15/09/1973.

${ }^{54}$ Ello se confirma en una de las cartas de Perón a su médico Antonio Puigvert, fechada el 15 de septiembre de 1973. Ver Peicovich, (2007). La compleja relación entre Perón y Pinochet osciló entre el enfrentamiento debido a la cercanía entre el primero y el general Carlos Prats, asesinado en septiembre de 1974 en Buenos Aires, y el famoso encuentro entre ambos mandatarios en la base aérea de Morón, oportunidad en la que firmaron una
} 
La cuestión de la salud del general no era un tema menor. Los documentos del Departamento de Estado así como los que cita Page de la CIA refieren claramente a la debilidad del primer mandatario y a la corta expectativa de vida. ${ }^{55}$ Eso contribuía al clima de inestabilidad política.

El asesinato de Rucci sin duda tendría efectos en la relación entre Perón y la izquierda del movimiento. Pureba de ello es la posterior aparición del «Documento Reservado» del Consejo Superior Peronista que convocaba a alejar a esos sectores, así como las instrucciones del general a los gobernadores para evitar el avance de esas líneas políticas en sus gestiones. ${ }^{56} \mathrm{El} 1^{\mathrm{O}}$ de octubre pronunciaría un discurso donde afirmó:

«Tanto el imperialismo capitalista como el imperialismo marxista -que a pesar de lo que muchos dicen existe también- se sienten todos los días en todos los países de la tierra: unos pretendiendo entrar por una penetración económica y otros pretendiendo hacerlo por una penetración ideológica que, en ambos casos, resultará al final una ocupación política o una ocupación militar, como ya hemos presenciado en muchas partes del mundo. Son esas fuerzas las que han creado los signos de la ultraderecha y de la ultraizquierda. Una, de la cual nosotros hemos sentido -durante estos últimos años especialmente- la influencia en nuestra política, en nuestra economía, y en el estado social deficiente en que encontramos el país. La otra, que comienza a aparecer bajo una nueva faz, la guerrilla» ${ }^{57}$

En línea con esa tendencia se destaca más adelante el reemplazo de Carcagno por Leandro Anaya. Su desplazamiento fue acordado con la dirigencia sindical y lopezrreguismo. Hegemonizaría a partir de allí una combinación entre una orientación derechista y la oposición al proyecto

declaración conjunta sobre la soberanía del territorio antártico. Eduardo Luis Duhalde afirma que allí se acordaron funciones de inteligencia y acción conjunta para la represión Duhalde, (1999): 127. Para una visión sobre la relación entre Argentina y Chile en este período ver Corigliano, (2002).

55 Ver Page, (1984): 280 y FRUS (1969-1976) Volume E-11, Part 2, Documents of South America 1973-1976, Argentina.

${ }^{56} \mathrm{El}$ texto completo del «Documento Reservado» puede consultarse en el Diario La Opinión, 2 de octubre de 1973, en «ंY esto qué es?», El Descamisado, Año 1, No 21, 9 de octubre de 1973 , p. 2, y se encuentra disponible en http://www.lagazeta.com.ar/ orden_reservada.htm. Ver también (Anguita y Caparrós,1998: 196-198). Para un análisis de avance de la represión durante el gobierno de Perón, ver (Bufano y Teixidó, 2015), y en particular respecto de la relación con las provincias «montoneras» ver (Servetto, 2010). ${ }^{57}$ Sidicaro, (1996): 99. 
de «pacto social»y «apertura hacia el Este» del ministro Gelbard, quien se fue encontrando gradualmente sin aliados. ${ }^{58}$

Esas decisiones se vinculaban con la profundización de la estrategia represiva a partir del ataque del Ejército Revolucionario del Pueblo a un cuartel en Azul en el mes de enero de 1974. Como anticipábamos, ello también tuvo su correlato en el desplazamiento del gobernador Oscar Bidegain, cercano a Montoneros, y su reemplazo por Victorio Calabró, representante de las 62 Organizaciones. Una clara avanzada de la línea sindical por sobre el ala izquierda del movimiento.

Existen diversas interpretaciones de la relación entre Argentina y Estados Unidos en el período. ${ }^{59}$ Aquí sostenemos de acuerdo al análisis de la bibliografía y de los documentos del Departamento de Estado que, a pesar de la reticencia de Vignes, muchos elementos de los que se iniciaron con Cámpora continuaron, pero eso se debió fundamentalmente a la presencia de Gelbard y la anuencia de Perón. Entre mayo de 1973 y octubre de 1974 Argentina firmó diez convenios y diversos acuerdos con Polonia, siete con Checoslovaquia, igual número con la URSS, once con Hungría, catorce con Rumania, seis con Alemania Oriental, dos con Bulgaria y cuatro con Yugoslavia. ${ }^{60}$ Lo que se modificaría era el nivel de afinidad política en el vínculo bilateral, tal como lo evidencian algunos documentos norteamericanos. En un informe sobre los rumores en círculos políticos y en la prensa local de un encuentro entre Perón y Nixon y del inicio de una «nueva etapa de cooperación» entre ambos países, elaborado por el embajador Lodge, éste destaca:

«Lo que impulsó esa opinión no es tanto el contenido de esos eventos, sino particularmente el evidente cálido y amistoso tono. Ese tono está muy alejado de la frialdad perceptible del lado argentino durante el período que siguió a la asunción del Presidente Cámpora en el pasado mayo» ${ }^{61}$

\footnotetext{
${ }^{58}$ Cisneros y Escudé (2000) 166

${ }^{59}$ Ver Russell, (2001): 131, Cisneros y Escudé, (2000):166 y Paradiso, (1993).

${ }^{60}$ Green, (1975): 93-95

${ }^{61}$ Foreign Relations of the Unites States (1969-1976) Volume E-11, Part 2, Documents of South America 1973-1976. Telegram 7789 From the Embassy in Argentina to the Department of State. US-Argentine Relations: A New Era? Buenos Aires, October 25, 1973., p. 23 [traducción propia]
} 
Perón priorizó algunas cuestiones que consideraba centrales. Es decir, el cambio respecto de los Estados Unidos no implicó el abandono de las tendencias abiertas con Cámpora, ni en lo que hace a la orientación hacia el Este, ni tampoco abiertamente respecto de la relación con América Latina en temas políticos. Lo mismo sucedió con la relación con el ingreso del país al Movimiento de No Alineados, algo que se concretó en 1973, en la IV Cumbre realizada en Argel. Para fines de 1973, la percepción de los Estados Unidos respecto de las tensiones internas, los virajes políticos y de la vinculación entre política externa y política interna era la siguiente:

«La Embajada ha tenido conocimiento a partir de sus fuentes de información que con respecto a la reforma de la OEA en la reciente reunión de Bogotá, Vignes dio instrucciones a la delegación argentina de evitar posiciones con pudieran 'avergonzar a su buen amigo Kissinger'. No obstante lo anterior el gobierno debe operar bajo ciertas restricciones de política, dado el actual estado de inflamado nacionalismo en la Argentina y los elementos heterogéneos (incluido el sector de la juventud radicalizada) que comprenden el movimiento justicialista de Perón (...) El gobierno argentino busca ser el puente entre Estados Unidos y el resto de Latinoamérica (...) y el mayor obstáculo en ese propósito es Brasil.» ${ }^{62}$

Perón era de algún modo el único y relativo punto de equilibrio entre esas tendencias en pugna, una tensión creciente que se iba definiendo a favor de los sectores vinculados al «peronismo familiar» y al conservadurismo de derecha. En el plano internacional, esas líneas eran reacias a la vinculación hacia el Este y al latinoamericanismo de la «Liberación» enunciado por Cámpora.

«El acercamiento a los Estados Unidos fue creciendo al compás del «cerco» que crecía en el continente. Los países vecinos diferían en sus políticas internas (... ) Lo que efectivamente se malogró fue el ingreso de la Argentina al Grupo Andino, algo que Puig y Cámpora habían anunciado desde un primer momento» ${ }^{63}$

\footnotetext{
${ }^{62}$ Foreign Relations of the Unites States (1969-1976) Volume E-11, Part 2, Documents of South America 1973-1976. Telegram 8459 From the Embassy in Argentina to the Department of State. Possible Meeting between President Nixon and Perón: Talking points. Buenos Aires, November 19, 1973, p. 27 [traducción propia]

${ }^{63}$ Cisneros y Escudé, (2000): 194.
} 
El nombramiento de Alejandro Orfila como embajador en Washington ratificaría el rumbo conciliatorio.

\section{Conclusiones: de la «Liberación» latinoamericana hacia la región como instrumento}

En efecto, el carácter ideológico de la «unidad latinoamericana» en el caso de Cámpora y en el de Perón no era el mismo. La nueva orientación hacia América Latina tuvo un impulso y auge en la corta gestión de Cámpora y ese impulso se extendió hacia el gobierno de Perón, pero siguiendo la tradición delineada por el líder desde sus primeros gobiernos. Las limitaciones provenían de la región, la disputa entre las potencias y de las tensiones dentro del movimiento peronista.

Como vimos, hay que destacar que en ese corto período, el escenario latinoamericano se fue modificando, con lo cual, las relaciones con Chile, Uruguay, Paraguay y Bolivia llevadas adelante con Perón se orientaron a cuestiones técnicas y económicas, soslayando las diferencias políticas con los regímenes que gobernaban esos países, caracterizados por el avance de la derecha y la nueva avanzada de los Estados Unidos en la región. Al mismo tiempo se recrudecían las diferencias dentro del peronismo y se acrecentaban las intenciones represivas dirigidas hacia los sectores del movimiento.

Por lo tanto, tal como la Tercera Posición había combinado elementos de pragmatismo y otros de autonomía, en su tercera presidencia, Perón, temeroso del avance no solamente de los Estados Unidos en la región, sino también de la Unión Soviética, buscó vincularse particularmente con Europa y dejó para América Latina un lugar central para la construcción de autonomía relativa.

Esa mirada implicaba una distancia del proyecto enarbolado por Cámpora, Puig y Gelbard. Quedaba atrás la vinculación con el Pacto Andino y la apelación a la Liberación revolucionaria. Sin embargo, se mantuvo la posición respecto de Cuba y en cuanto a la relevancia de los vínculos en la Cuenca del Plata.

Las luchas intestinas dentro del peronismo condicionaron el devenir de la política internacional y viceversa. El gobierno de Isabel, luego de la muerte de Perón, constituyó el claro escenario de recrudecimiento de esa disputa, pero en un contexto de avance de las potencias y de las clases dominantes. 
El período estudiado demuestra que existe una profunda vinculación entre variables internas y externas para explicar las relaciones internacionales y que analizarlo requiere de ir desatando los sucesos para evidenciar la profunda imbricación entre la dinámica de la Guerra Fría y la política interna de la Argentina. Por ello, no hay cortes y rupturas lineales, porque tanto en los sectores civiles como en el seno del Estado, las líneas promotoras de determinada inserción internacional se van yuxtaponiendo, en constante conflicto, dando lugar a la hegemonía temporaria de alguna de ellas, pero no por esa razón, descartando la existencia de las otras. Hemos intentado mostrar que este enfoque nos permite abordar la complejidad y analizar la política exterior a partir de una mirada histórica y social global.

\section{Bibliografía}

BONASSO, Miguel, (2006), El presidente que no fue. Buenos Aires: Planeta.

BRAUDEL, Fernand, (1993), «Renacimiento, reforma, 1968: revoluciones culturales de larga duración», en La Jornada Semanal, n. 226, octubre de 1993.

BUFANO, Sergio y TEIXIDÓ, Lucrecia, (2015), Perón y la Triple A. Buenos Aires: Sudamericana

CISNEROS, Andrés y ESCUDÉ, Carlos (2000), Historia General de las Relaciones Exteriores de la República Argentina, Parte III Las relaciones exteriores de la Argentina subordinada (1943-1989). Tomo XIV Las relaciones politicas (1966-1989). Buenos Aires: Grupo Editor Latinoamericano, Nuevo Hacer.

CORIGLIANO, Francisco, (2002), «Las vinculaciones entre Argentina y Chile (1973-1976) El doble canal de vinculación», en Revista Postdata $\mathrm{N}^{\mathrm{O}} 8$, Buenos Aires, pp. 159-195.

CORIGLIANO, Francisco, (2007), «Colapso estatal y política exterior: el caso de la Argentina (des)gobernada por Isabel Perón (1974-1976)», Revista SAAP, Vol 3. $\mathrm{N}^{\mathrm{O}}$ 1, pp. 55-79.

DE PABLO PARDO, Luis María, (2016), Entrevista realizada por Rapoport, Mario. Rapoport, Mario (comp.) Historia Oral de la Politica Exterior Argentina. Tomo II. Buenos Aires: Octubres. 
DUHALDE, Eduardo Luis, (1999), El Estado terrorista argentino: Quince anPos despueis, una revisioin criitica. Buenos Aires: EUDEBA.

FURMAN, Rubén, (2014), Puños y pistolas. La extraña historia de la Alianza Libertadora Nacionalista. Buenos Aires: Sudamericana.

GORDILLO, Mónica, (2007), «Protesta, rebelión y movilización. De la resistencia a la lucha armada» en James, Daniel (2003) Violencia, proscripción y autoritarismo (1955-1976) Nueva Historia Argentina. Buenos Aires: Sudamericana.

GREEN, Raúl, (1975), «Documentación; los instrumentos de la apertura a los países de economía centralmente planificada», en Revista Argentina de Relaciones Internacionales, CEINAR, año 1, número 3, septiembre-diciembre, Buenos Aires.

LAUFER, Rubén y SPIGUEL, Claudio, (1998) «Europa Occidental en las relaciones internacionales argentinas del mundo bipolar, 19701990», en Revista Ciclos en la historia, la economía y la sociedad, $\mathrm{N}^{\mathrm{O}}$ 14-15, ler. semestre.

HOROWICZ, Alejandro, (1973), «Concluye el aislamiento comercial de Cuba respecto de América Latina», Diario La Opinión, 8 de agosto de 1973, p. 11.

MÍGUEZ, María Cecilia, (2013b), «La visita de De Gaulle a la Argentina y las repercusiones en las fuerzas políticas internas», en Revista Relaciones Internacionales, vol, $22, \mathrm{n}^{\circ} 45$, Instituto de Relaciones Internacionales, La Plata.

MORGENFELD, Leandro, (2014), «Argentina y Estados Unidos, golpe a golpe (1966-1976)» en Revista $S A A P$ vol.8, no.2, Buenos Aires.

MUSACCHIO, Andrés, (2006), «De la ALALC al Mercosur: la experiencia argentina», en MORGENFELD, Leandro (comp.) El Mercosur en cuestión. Buenos Aires: Ediciones Cooperativas.

PAGE, Joseph A., (1984), Perón. Segunda Parte (1952-1974). Buenos Aires: Ediciones Javier Vergara.

PARADISO, José, (1993), Debates y trayectorias de la politica exterior argentina. Buenos Aires: Grupo Editor Latinoamericano.

PEICOVICH, Esteban, (2007), El ocaso de Perón. Buenos Aires: Marea.

PERINA, Roberto y RUSSELL, Roberto, (1988), Argentina en el mundo. Buenos Aires: Grupo Editor Latinoamericano.

PUCCIARELLI, Alfredo, (1999), «La primaciìa de la polìtica. Lanusse, 
Peroìn y la Nueva Izquierda en tiempos del GAN», en TORTTI, Mariìa, Protesta social y «Nueva Izquierda» en la Argentina del Gran Acuerdo Nacional. Buenos Aires: Eudeba. pp. 205-234.

PUIG, Juan Carlos, (1988), "Poliitica Internacional Argentina", en Perina, Roberto y Russell, Roberto, Argentina en el mundo. Buenos Aires: Grupo Editor Latinoamericano.

PUIG, Juan Carlos, (2016), Entrevista publicada en RAPOPORT, Mario (comp.) (2016) Historia Oral de la Politica Exterior Argentina, Tomo II. Buenos Aires: Octubre.

RAPOPORT, Mario, (1986), Politica y diplomacia en la Argentina. Buenos Aires: Tesis.

RAPOPORT, Mario, (1995), «La Argentina y la Guerra Fría. Opciones económicas y estratégicas de apertura hacia el Este (1955-1973) en Revista Ciclos en la Historia, la economía y la sociedad, Año V, vol. 8, Buenos Aires, ler. Semestre.

RAPOPORT, Mario y SPIGUEL, Claudio, (2009), Relaciones Tumultuosas. Estados Unidos y el primer peronismo. Buenos Aires: Emecé.

RAPOPORT, Mario (comp.), (2016), Historia Oral de la Politica Exterior Argentina, Tomo II. Buenos Aires: Octubre.

RUSSELL, Roberto, (2001), "La polìitica internacional (1945-1983)» en Academia Nacional de la Historia. Nueva Historia de la Nacioin Argentina. Tomo VIII. Buenos Aires: Planeta.

SERVETTO, Alicia, (2010) 73/76. El gobierno peronista contra las «provincias montoneras». Buenos Aires: Siglo XXI.

TULCHIN, Joseph, (1990), La Argentina y los Estados Unidos: Historia de una desconfianza. Buenos Aires: Planeta.

SIDICARO, Ricardo, (1996), Los nombres del poder: Juan Domingo Perón. Buenos Aires: FCE.

SHEININ, David, (2006), Argentina and the United States. An Alliance Contained, Atenas, University of Georgia.

SVAMPA, Maristella, (2003), «El populismo imposible y sus actores (19731976)» en James, Daniel Violencia, proscripción y autoritarismo (19551976) Nueva Historia Argentina. Buenos Aires: Sudamericana.

TCACH, César, (2007), «Golpes, proscripciones y partidos políticos», en James, Daniel (2003) Violencia, proscripción y autoritarismo (19551976) Nueva Historia Argentina. Buenos Aires: Sudamericana. 
VACS, A. J., (1984), Los socios discretos. Buenos Aires: Sudamericana. 